of recent formation consists merely of cedema of the epithelial layers of the cord, and if the cause is persistent there follow epithelial hyperplasia, keratinisation, and lastly, thickening of the adjacent connective tissue. Operative treatment probably becomes necessary when the last two stages have been reached.

With regard to Group 2, laryngeal growths generally are very uncommon, and are shown by hospital statistics to constitute only about 1.25 per cent. of purely laryngeal diseases. ${ }^{5}$ of these papillomata are the most frequent variety, true fibromata being very rare. Of 100 cases of simple growths published by Sir Morell Mackenzie, 10 per cent. were fibromata but only two resembled my cases. ${ }^{6}$ Dr. Wyatt Wingrave has, however, examined and published a large number and has, I believe, examined many more since. ${ }^{7}$ Whereas in Case 4 the clinical picture is indistinguishable from that of typical fibroma, the microscope reveals the fact that the growth is of epithelial and not connective origin. This contradiction is not uncommon. Of the other two, it is probable that only Case 1 can be considered a true fibroma, Case 3 being a product of inflammatory and mechanical irritation. The three well-recognised predisposing factors in the origin of laryngeal growths are present in Cases 3 and 4-namely, nasal obstruction or disease, laryngitis, and over-use of the voice. If Cases 2 and 3 be compared as regards their etiology and site, it would appear that they differ chiefly in degree, for owing to the laryngitis in Case 3 the mucous membrane covering the cords was soft and swollen, a condition unfavourable to the formation of a " hard corn." The friction, however, with the opposite cord resulted in the irritation and clotting in the congested vessels of the submucous tissue, which in turn stimulated growth in its immediate vicinity. The occurrence of such a growth therefore is no mere accident, but a direct result of the occupation of the patient. No such sequence of events can be suggested as the origin of the growth in Cases 1 and 4, but it is probable that in Case 4 the patient had been using "unwisely and too well" her voice, before the complete subsidence of one of her attacks of laryngitis, resulting in some endo- or extra-vascular clotting, which was the original irritating source of the growth.

In conclusion, it may be said that efficient nasal breathing and the correct use of the voice will prevent the occurrence of such growths in those predisposed; and should such growths occur the methods I have advocated for their removal would greatly minimise the risks of damaging the vocal cord and thus the best results be expected.

Wimpole-street, $\mathrm{W}$.

\section{THE INFANT IN THE SCHOOL MEDICAL EXAMINATION.}

BY A. D. EDWARDS, M.B., B.S. LoND., B.Sc., D.P.H., L.R.C.S. EDIN., L.F.P.S. GLASG., \&O.

DEPUTY MEDICAL OFFICER OF HEALTH AND ASSISTANT SCHOOL MEDICAL OFFICER TO THE COUNTY BOROUGH OF NEWPORT, MON.

THE examination of the infant of four or five years of age forms a large part of the work of the school medical officer and as this class is, on account of the tender years of children, the most difficult to deal with, it is necessary that the examination should be conducted warily and with the least possible disturbance to the child. It is not sufficient that the examining medical officer should exhibit in a general way the characteristics of tact and kindness; for if one timid infant returns to its class frightened and tearful after the medical examination it is certain that many, if not most, of the other children from that class will come to the examining room with a predisposition to cry and to be frightened, and there will then be an increased possibility of a large number of examinations being carried out under the most disadvantageous circumstance- that of a frightened, crying child.

Fear of the unknown is well marked in all children, and in the infant class with which we are dealing it is probably the most powerful instinct next to that of mother-love. Only a few months before the medical examination these children of four or five years of age have made their first venture out

5 Lennox Browne: Diseases of the Throat and Nose, p. 651.
6 Morell Mackenzie: Essays nn Innocent Growths of the Larynx

7 Wyatt Wingrave : Journal of Laryngology, Rhinology, and Otology, vol. xxi., p. 5 . of the home circle into the daily school life, and their instinctive fear of the unknown and of the unusual is often increased by certain attendant circumstances. Under most education authorities a notice is sent to the parents invitingone of them to attend at the medical examination of the child, and a frequent result of this is that the child hears the subject discussed at home and obtains an erroneous impression of the matter to which its own faculty of imagination contributes largely. Another result of this notification is that on the morning of the examination the child often receives an unusually thorough washing and scrubbing and is then arrayed in clothes which are donned only on Sundays and special occasions. The unusually vigorous ablution and the wearing of Sabbath apparel mark out the day as being special; from the home conversation the child has gathered that it is not a picnic or other pleasuregiving day, and by the time it arrives at school an excitable child will be in a state of nervous tension, which, if its feelings are not carefully studied during the examination, will surely end in fright and tears and thus render the examination a matter of extreme difficulty; and the return of such a child to its class will result in much trouble in the examination of children immediately following. So that although with ordinary care a number of normal infants of four or five years of age may be examined successfully without one of them crying or being frightened, it is most important that the examination should be conducted in such a way that even a nervous or timid child should be put at ease, and indeed it should be the object of the examining medical officer to make the child interested in the examination-an object which, if suitable means are employed, is neither impossible. nor difficult.

With the object of making a good start it is well that when the infant enters the examining room there should not be more than two or three adults present. It is neither necessary nor wise to have in the room any adult besides the medical officer, the school nurse, and the head teacher. If the latter is an efficient administratrix she will be well known to the child, who will look upon her as a friend, but it will be found that the presence of the child's mother more often hinders than aids the examination, and in most cases a timid child will respond more readily to tact and kindness from the medical officer in the absence of the mother-a fact which is explained by the instinct of the child to run to its mother in the presence of strangers.

Important information concerning the child's previous illnesses, general health, \&c., can be obtained at a preliminary interview with the mother, and in this connexion it, may be noted that an opinion of the child's mental capacity should be obtained not only from the head teacher but also from the governess who has most to do with the child. In the case of a very timid child, the presence of another child from the same class, preferably one who has been examined and has "made friends" with the medical officer, is an advantage, but it is inadvisable to keep one child waiting its turn and watching the examination of another.

The order of the examination is important. Thus the weighing and measuring should not be done first, for an infant is apt to become uneasy if made to stand on the scales immediately after entering the room, so that the proceeding should be left until the child's interest and confidence have been gained; nor should the mouth and throat, be examined until the end. Two things should be avoided during the examination-fussiness and sudden and rapid movements. The confidence of a nervous infant may be won by gentle attention, but to be fussed over by two or three adults at the same time is to the liking of no child.

The distrust of jerky and sudden movements which is displayed by infants of four or five years is the same instinct which is described by Richard Jefferies as existing in wild animals, and gentleness in voice and gesture should be therefore the habit of every school medical officer. Although toys are useful in estimating the mental capacity of the infant their rontine use during the examination is not to be recommended, for the interest of the child should be centred in the medical officer and in what he says rather than in an external object; and, moreover, although the toys may help to put a child at ease and to prevent fright during the examination, they may be so attractive that the parting with them at the end of the examination will result in a flood of tears. The examination of the child should begin as soon as it enters the room, for the faculty of keen observation should be developed so as to give the fullest 
information concerning the child, and the gencral appearance, gait, and pose of the head may be observed at a glance, and the presence of the adenoid facies, rickets, or deformities should also be noticed. Before the examination of the chest is proceeded with the child should be spoken to and encouraged to speak and to become used to the stethoscope which, with a little suggestion, may be regarded as a new kind of toy. Not a few children are inclined to look apon the stethoscope with distrust, but their aversion may be very readily overcome by asking them to hold the chest-piece to the ear in order to "hear the bird sing," and whilst the piece is held to the ear a sibilant whistle may be produced, the tip of the tongue being placed behind the upper incisor teeth, approximating to its position in the act of hissing. The lips should not be used in the production of this sound, which is the best test of a child's hearing, and with a little experience the intensity can be varied so that a standard for normal hearing can be obtained. The fact that the little bird is heard to whistle must be ascertained not by questioning but by observing the child's face, for the resulting smile is not only almost invariable but is the most valuable affirmation to be obtained. During this performance, which need not take more than 30 seconds, the school nurse should be loosening the infant's clothing, and the child should by this time be interested enough to place the stethoscope on its chest when asked to do so, and it will be an advantage to allow the little hand to remain on the end of the stethoscope whilst it is moved to different parts of the chest.

The weighing and measuring of the child may now be undertaken, after which the manual examination for the submaxillary and cervical glands should be done. For this the child must bend the head downwards in order to relax the cervical muscles, and this opportunity is favourable for the inspection of the condition of the scalp and head at the crown; in the same way the sides of the head may be inspected whilst the examination for external ear disease is proceeding. The infant is less likely to be frightened by this part of the examination, but it is well to retain the child's interest by talking; and, indeed, it is a golden rule that throughout the examination the child should not be too conscious of the fact that it is being examined. The examination of the mouth and throat is left until late because it disturbs the child most, and in this connexion the shape and material of the spatula are not unimportant. Vulcanite is to be preferred to metal, the coldness of which makes it uncomfortable for the child; when the instrument is disinfected by means of biniodide or other compound of mercury, metal of course cannot be used. Here also reference may be made to the question of the advisability of giving sweets to the child. It is true that the school medical officer should rely on his tact and manner to win for him the infant's confidence, but there are not a few cases in which the appeal to "cupboard love" is necessary, and in which the giving of a small sweet will make the difference between an examination of a crying, struggling child and one which is done quietly, pleasantly, and successfully. Particularly useful is the giving of a sweet in the examination of the mouth and throat, for however reluctant the little one is to allow its mouth and throat to be examined, it will almost invariably allow the doctor to "see if the sweet is finished," and the whole process of the examination will be regarded as part of a game, and even the last slight pressure of the spatula on the tongue which is necessary to reveal the tonsils will not interfere with the smile which comes when the examination is finished.

Thus it will be seen that by methods which the above remarks indicate in a cursory manner the infant may be not only interested in the examination but may be made to enter into it as a game; and such methods will be found to be particularly useful in the case of timid and nervous infants who, if frightened, would be found to be difficult and even impossible to examine fully without physical force. 'Too much attention should not be paid to quiet crying in an infant, and it has at least one advantage that the occasional long-drawn inspiration gives one a good opportunity of listening to the lung sounds. But even gentle crying should be a rare occurrence, and by tact and kindness and the use of suitable methods the confidence of the most timid infant of four and five years may be won by the true lover of children.

Newport, Mon.

\section{Clinital d dotes:}

\section{MEDICAL, SURGICAL, OBSTETRICAL, AND} THERAPEUTICAL.

\section{A CASE OF SEPTIC PLEURISY AND PERICARDITIS RUNNING AN AFEBRILE COURSE; DEATH WITHIN SIX DAYS OF ONSET OF SYMPTOMS.}

By C. W. Windsor, M.A., M.D. CANTAB.

THE patient was a thoroughly healthy man, aged 40 years, living in a country village, occupying himself with farming for a living and shooting for sport. The only previous illness of consequence was a severe attack of pleurisy 16 years ago; but ten weeks before the onset of the illness to be described below he had a very sharp attack of shingles which pulled him down somewhat. On each of the three days before the beginning of the fatal illness he had been out shooting, and beyond being a little fagged was in apparently good health. On Sept. 28th at tea he complained of his throat being stiff and full but dir not make much fuss about it. This condition became much worse during the night, so that a medical man was sent for early next morning, when the uvula was found to be much swollen, almost blocking the fauces and interfering considerably with breathing. His temperature was $99^{\circ} \mathrm{F}$. Later in the day this œdematous swelling was freely scarified, to the patient's relief; his temperature rose in the evening to $102^{\circ}$. Next morning, Sept. 30th, the swelling of the uvula and soft palate had subsided but the patient looked ill with rather a cyanosed complexion; his temperature was $101^{\circ}$, his breathing was quick and shallow, his voice had almost gone, and swallowing was difficult, the symptoms pointing to some œdema of the glottis ; the pulse was rapid. During the night he complained of very severe pain in the upper part of the abdomen, especially over the liver. On examination of the chest friction sounds were heard over the lower part of the right lung, the axilla, and also at the left base behind; while over the cardiac area there were abundant soft crepitations but no pericardial friction. There was no expectoration. The temperature was $99^{\circ}$, the respirations were 40 , and the pulse was 120. The beart sounds were clear. The urine and abdominal viscera were normal. The uvula and mouth were healthy. The skin was perspiring freely. The feet were cold. There was cyanosis of the face. This condition of things quickly developed into well-marked pleurisy at each base, with some consolidation of the underlying lung tissue. Expectoration was slightly rusty coloured. The temperature remained normal but the pulse-rate varied between 140 and 160 and respirations were from 40 to 50 . There was a constant desire to sit up in a chair, as he could not rest in bed. The face was a bad colour and the patient was greatly exhausted and suffered from sleeplessness. His mind was quite clear. In this condition the patient was seen in consultation by Dr. Laurence Humphry. Without development of further physical signs the condition became rapidly worse and the patient died on Oct. 5th after six days' illness.

Nothing special beyond pneumococci was found on bacteriological examination of sputum. Treatment was on ordinary lines with a view to promote sleep, to relieve pain, and to maintain strength. Antistreptococcic serum was injected, oxygen and hypodermics of strychnine were freely used. At the post-mortem examination there was very intense pleurisy on each side with membrane a quarter of an inch on both surfaces of the pleura, also consolidation of the lung in each lower lobe. The whole pericardium was lined with a similar thick membrane, showing a reticulated surface and resembling uncooked tripe. There was some congestion of the larynx. There was considerable enlargement of the spleen. Cultivation orowths from the affected viscera showed staphylococci and streptococci, pneumococci, and also a large bacillus resembling bacillus anthracis but which proved to be a vutrefactive organism. The interest of this case lies more in the speculation as to its origin than in the actual lesions. The odematous swelling of the uvula and soft palate was 